\title{
Objective Accommodative Amplitude and Dynamics with the 1CU Accommodative Intraocular Lens
}

\author{
James Stuart Wolfsobn, ${ }^{1}$ Olivia Anne Hunt,${ }^{1}$ Shebzad Naroo, ${ }^{1}$ Bernard Gilmartin, ${ }^{1}$ \\ Sunil Shab, ${ }^{2,3,4}$ Ian Andrew Cunliffe, ${ }^{2,3,4}$ Mark Timothy Benson, ${ }^{2,3,4}$ and Sanjay Mantry ${ }^{4}$
}

Purpose. To compare the objective accommodative amplitude and dynamics of eyes implanted with the one-compartmentunit (1CU; HumanOptics AG, Erlangen, Germany) accommodative intraocular lenses (IOLs) with that measured subjectively.

Methods. Twenty eyes with a 1CU accommodative IOL implanted were refracted and distance and near acuity measured with a logMAR (logarithm of the minimum angle of resolution) chart. The objective accommodative stimulus-response curve for static targets between 0.17 and $4.00 \mathrm{D}$ accommodative demand was measured with the SRW-5000 (Shin-Nippon Commerce Inc., Tokyo, Japan) and PowerRefractor (PlusOptiX, Nürnberg, Germany) autorefractors. Continuous objective recording of dynamic accommodation was measured with the SRW-5000, with the subject viewing a target moving from 0 to $2.50 \mathrm{D}$ at $0.3 \mathrm{~Hz}$ through a Badal lens system. Wavefront aberrometry measures (Zywave; Bausch \& Lomb, Rochester, NY) were made through undilated pupils. Subjective amplitude of accommodation was measured with the RAF (Royal Air Force accommodation and vergence measurement) rule.

Results. Four months after implantation best-corrected acuity was $-0.01 \pm 0.16 \log$ MAR at distance and $0.60 \pm 0.09 \log$ MAR at near. Objectively, the static amplitude of accommodation was $0.72 \pm 0.38 \mathrm{D}$. The average dynamic amplitude of accommodation was $0.71 \pm 0.47 \mathrm{D}$, with a lag behind the target of $0.50 \pm 0.48$ seconds. Aberrometry showed a decrease in power of the lens-eye combination from the center to the periphery in all subjects (on average, $-0.38 \pm 0.28 \mathrm{D} / \mathrm{mm}$ ). Subjective amplitude of accommodation was $2.24 \pm 0.42 \mathrm{D}$. Two years after 1CU implantation, refractive error and distance visual acuity remained relatively stable, but near visual acuity, and the subjective and objective amplitudes of accommodation decreased.

Conclusions. The objective accommodating effects of the 1CU lens appear to be limited, although patients are able to track a moving target. Subjective and objective accommodation was reduced at the 2-year follow-up. The greater subjective amplitude of accommodation is likely to result from the eye's depth of focus of and the aspheric nature of the IOL. (Invest Oph-

From the ${ }^{1}$ School of Life and Health Sciences, Aston University, Birmingham, United Kingdom; the ${ }^{2}$ Midland Eye Institute, Birmingham, United Kingdom; the ${ }^{3}$ Solihull Hospital, Birmingham, United Kingdom; and the ${ }^{4}$ Birmingham and Midland Eye Centre, Birmingham, United Kingdom.

Submitted for publication July 20, 2005; revised October 13, 2005; accepted January 24, 2006.

Disclosure: J.S. Wolffsohn, None; O.A. Hunt, None; S. Naroo, None; B. Gilmartin, None; S. Shah, HumanOptics AG (F), Lenstec Inc. (F), Bausch \& Lomb (F); I.A. Cunliffe, None; M.T. Benson, None; S. Mantry, None

The publication costs of this article were defrayed in part by page charge payment. This article must therefore be marked "advertisement" in accordance with 18 U.S.C. $\$ 1734$ solely to indicate this fact.

Corresponding author: James Stuart Wolffsohn, School of Life and Health Sciences, Aston University, Aston Triangle, Birmingham B4 7ET, UK; j.s.w.wolffsohn@aston.ac.uk. thalmol Vis Sci. 2006;47:1230-1235) DOI:10.1167/iovs.050939

$\mathrm{P}$ resbyopia is a condition of age, rather than ageing, whereby the normal age-related reduction in amplitude of accommodation reaches a point at which the clarity of vision at near cannot be sustained long enough to satisfy the individual's requirements. ${ }^{1}$ The ability to accommodate is essentially lost by the age of 55 years. $^{2}$ Techniques such as impedance cyclography, ultrasound biomicroscopy, and magnetic resonance imaging (MRI) have shown that the ciliary muscle retains much of its contractility throughout life..$^{3-5}$ MRI studies of the human eye have shown that for distant viewing, the crystalline lens diameter remains constant, and the ciliary collar diameter decreases with age. ${ }^{5}$ Laser scanning techniques on in-vitro material suggest that crystalline lens ageing is the principal structural correlate for the loss of accommodation in presbyopia. ${ }^{6}$ Such studies fail to provide support for recent surgical techniques using scleral expansion bands developed from unconventional theories proposing that the distance between the ciliary muscle and lens equator is reduced with age due to lens growth, causing the zonules to slacken and the lens to bow into a relaxed position. ${ }^{7}$

Replacing the natural lens with a multifocal intraocular lens (IOL) has been described as an effective surgical method to obtain clear vision at both near and distance. ${ }^{8-10}$ However, it can lead to a reduction in visual function such as contrast sensitivity $^{11,12}$ and to symptoms such as glare. ${ }^{13}$ Mimicking pseudophakic accommodation by refilling the lens capsule with a viscoelastic substance, similar to that found in the young crystalline lens, has received some attention. ${ }^{14-16}$ However, the proposed principal action of accommodating IOLs currently on the market is an anterior shift. ${ }^{17-19}$

Subjective amplitude of the accommodation of accommodating IOLs has been measured in several studies and found to be on average 1.33 to $2.36 \mathrm{D}^{20-25}$ However, the subjective amplitude of accommodation of a single-piece conventional IOL is approximately 0.42 to $1.08 \mathrm{D}$, due to depth of focus and the optical aberrations of the human visual system. ${ }^{22,25} \mathrm{~A}$ subjective technique of defocusing with ophthalmic lenses has indicated a mean accommodation of $\sim 1.6 \pm 0.5 \mathrm{D}$ with the 1CU (HumanOptics AG, Erlangen, Germany) accommodating IOL compared with that of a single-piece, conventional IOL of $0.55 \pm 0.33 \mathrm{D}^{24,25}$

Attempts to quantify the range of accommodation objectively have included measurement of lens movement, streak retinoscopy, aberrometry and photorefraction. ${ }^{23-26}$ Quantification of IOL movement has been performed with ultrasound, ${ }^{24,25,27-29}$ image analysis, ${ }^{29}$ and partial coherence interferometry, ${ }^{2,24,25,29,30}$ before and after ciliary muscle contraction using pilocarpine or phenylephrine. The movement of the lens on maximum contraction varies greatly between these studies and between measurement techniques, being on average between 100 and $1040 \mu \mathrm{m}$. Approximate objective accommodative range has then been modeled from this movement. It is unknown whether pharmacologically in- 
duced accommodation is due to the same effect on the accommodative structure as physiologically induced accommodation.

Streak retinoscopy to static targets $(5.00 \mathrm{~m}$ vs. $0.35 \mathrm{~m})$ has shown an average range of physiological accommodation of 1.0 to $1.2 \mathrm{D}$ for the $1 \mathrm{CU}$ accommodating IOL compared with $\sim 0.2 \pm 0.2 \mathrm{D}$ for the single-piece conventional IOL control group. ${ }^{22,24,25}$ Dynamic $(7 \mathrm{~Hz}$ ) aberrometry to stepped distance and near targets has shown changes in defocus of up to $1.0 \mathrm{D}$, with an average of $0.46 \mathrm{D} .^{26}$ Photorefraction using the difference in PowerRefractor (SRW-5000; Shin Nippon, Tokyo, Japan) measures with subjects viewing at $5.00 \mathrm{~m}$ compared with $\sim 0.35 \mathrm{~m}$ have shown a mean amplitude of $1.00 \pm 0.44 \mathrm{D}$ compared with $0.35 \pm 0.26 \mathrm{D}$ for the single-piece conventional IOL control group. ${ }^{25}$

None of the studies assessing the accommodative facility achieved with an accommodative IOL have quantified the stimulus response curve or the dynamic accommodative response to a moving stimulus, ${ }^{2}$ and therefore this study aims to measure these features in patients fitted with the 1CU accommodative IOL. Determining the accommodative stimulus response curve will identify whether the pseudophakic accommodation with an accommodative IOL continues to increase with increasing accommodative demand, asymptotes when accommodative demand exceeds the pseudophakic accommodative range, or even decreases with increased target blur past a peak when the pseudophakic accommodative demand and response are matched. The dynamic accommodative response to a moving stimulus will determine whether the pseudophakic accommodative response is similar in dynamic amplitude to the static amplitude and whether the time course (time lag between the stimulus and response) is similar to that of prepresbyopic accommodation.

\section{MethodS}

Twelve subjects aged 33 to 78 years (average, $60.7 \pm 15.4$; three men, nine women) gave informed consent to take part in the study. All had had phacoemulsification cataract surgery and insertion of a one-component-unit (1CU) accommodative IOL (HumanOptics AG, Erlangen, Germany) implanted in one (four subjects) or both (eight subjects) eyes (20 eyes in total). Inclusion- exclusion criteria were a lenticular opacity affecting the visual demand of the subject, in an otherwise healthy eye (no other ophthalmic abnormality such as diabetic retinopathy, glaucoma, corneal problems or macular problems). The patients received bilateral 1CUs if both eyes met the inclusion- exclusion criteria. Each subject underwent a full subjective binocular refraction at $6 \mathrm{~m}$. Informed consent was obtained from the subjects after explanation of the nature and possible consequences of the study. The research complied with the tenets of the Declaration of Helsinki and was approved by institutional review board.

The $1 \mathrm{CU}$ lens is a single-piece, hydrophilic, acrylic, ultravioletinhibited IOL with a refractive index of 1.46. It has been shown to result in stable refraction and subjective accommodation over a 1-year period. ${ }^{31}$ The central optic portion, $5.5 \mathrm{~mm}$ in diameter, is designed to rest postcapsularly after the crystalline lens matrix has been removed by phacoemulsification cataract surgery. The optic has a hinged connection to four haptic legs, which are thinner near the optic, to aid flexibility and allow movement of the optic anteriorly, secondary to ciliary muscle contraction.

The first assessment was conducted a mean of $127.7 \pm 70.9$ days after lens implantation. After retinoscopy and subjective refraction, best corrected threshold letter acuity was measured at far with high (90\%) and low (10\%) contrast (at $3 \mathrm{~m}$ ) and near threshold word acuity at near $(40 \mathrm{~cm})$ with logMAR (logarithm of the minimum angle of resolution) progression charts. ${ }^{32}$ Each letter was scored as 0.02 $\operatorname{logMAR}$, and guessing was encouraged. Subjects with residual refractive error after surgery were made functionally emmetropic with ultrathin soft contact lenses (Acuvue Dailies, HEMA [hydroxyethyl methacrylate], 58\% water content material; Vistakon, Johnson \& Johnson, Jacksonville, FL) to ensure that the accommodative demand of the viewing task for each subject was virtually identical.

Amplitude of accommodation was measured with an RAF (Royal Air Force accommodation vergence measurement) binocular gauge (ClementClarke/Haag-Streit, Harlow, UK). Subjects viewed the N6 $(0.75 \mathrm{M}$ units) size letters from a distance of $50 \mathrm{~cm}$. The letters were moved (approximately $5 \mathrm{~cm} / \mathrm{s}$ ) toward the subject, until the letters were no longer resolvable. The target was then moved to $10 \mathrm{~cm}$ from the subject and steadily moved away from them until the letters were first resolvable. The reciprocal of the average distance between these two measures was taken as the subjective amplitude of accommodation in diopters.

Accommodative responses were measured with the PowerRefractor (PlusOptiX, Nürnberg, Germany) ${ }^{33}$ and the SRW-5000 (Shin-Nippon Commerce Inc., Tokyo, Japan) ${ }^{34}$ autorefractors through undilated pupils in a randomized order. The subject's head was positioned on a head and chin rest. The PowerRefractor was positioned $1 \mathrm{~m}$ from the subject, aligned with the right eye, but positioned to image both of the subject's eyes. The SRW- 5000 was aligned with the visual axis of the eye under examination and measured the accommodative response of this eye only, although the subject had a binocular open-field view of the targets. Subjects viewed a static $90 \%$-contrast Maltese cross located at $0.17,0.50,1.00,1.50,2.00,2.50,3.00$, and $4.00 \mathrm{D}$ of accommodative demand $(6.00,2.00,1.00,0.75,0.50,0.40,0.33$, and $0.25 \mathrm{~m}$, respectively), in real space (matched for angular subtense and luminance), in random order. Five static readings were taken with both the PowerRefractor (full-refraction mode) and SRW-5000 at each distance. All patients were asked to focus on the target and to try to keep it clear, as if they were reading, while the measurements were obtained. ${ }^{35}$ The luminance of the targets was kept constant at 40 lux. This particular luminance was chosen to maintain a pupil size adequate to achieve measurements at all distances with the PowerRefractor. ${ }^{36}$ The luminance was kept the same for the SRW-5000 measures, so as not to affect the stimulus response curve. ${ }^{37}$

Continuous recording of dynamic accommodation was measured with the SRW-5000 with the subject viewing a target moving from 0.0 to $2.5 \mathrm{D}$ at $0.3 \mathrm{~Hz}$ through a $+5.0 \mathrm{D}$ Badal lens system. The SRW-5000 is able to monitor the accommodative response dynamically, with high resolution and a frequency of up to $60 \mathrm{~Hz}{ }^{38}$ The data were smoothed by averaging the 10 time points on either side (approximately 0.2 seconds), and blinks were removed. ${ }^{39}$ The dynamic amplitude of accommodation and time lag was calculated from the average of five cycles.

Aberrations across the undilated pupil were quantified with a wavefront-sensing device (Zywave; Bausch \& Lomb, Rochester, New York) that is based on the Hartman-Shack principle. ${ }^{40}$ The measured deviation of the 780-nm wavefront (at 70-75 locations within the pupil area) as it passed through the optics of the cornea and IOL was assessed in terms of lower order aberrations (i.e., sphere and cylinder, combined to give a predicted photopter refraction [PRP] term).

Subjects' refraction, best corrected distance and near visual acuity, objective accommodative stimulus response curve (measured with the SRW-5000) and subjective amplitude of accommodation were remeasured a mean of $695.4 \pm 124.6$ days after phacoemulsification cataract surgery. Lenticular capsule clarity was also assessed by an ophthalmologist with a slit lamp biomicroscope.

Static prescriptions were converted into mean spherical equivalents (MSEs), and the slope and Pearson's product moment coefficients were calculated.

\section{Results}

At 4 months after lens implantation, the residual MSE refractive error of the group, as represented by the subjective refraction, was $-0.71 \pm 0.44 \mathrm{D}$. The distribution of residual refractive error is presented in Figure 1. The mean best-corrected dis- 
A

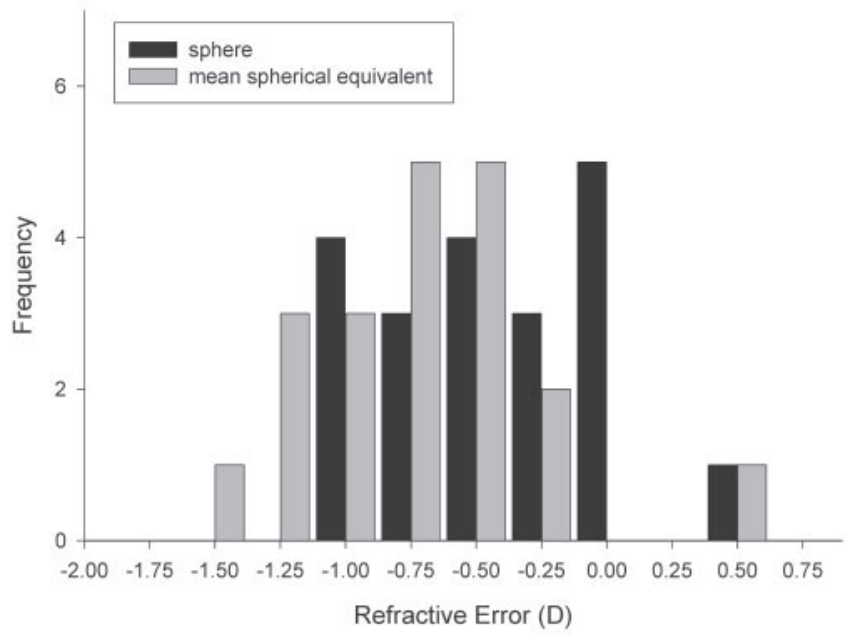

B

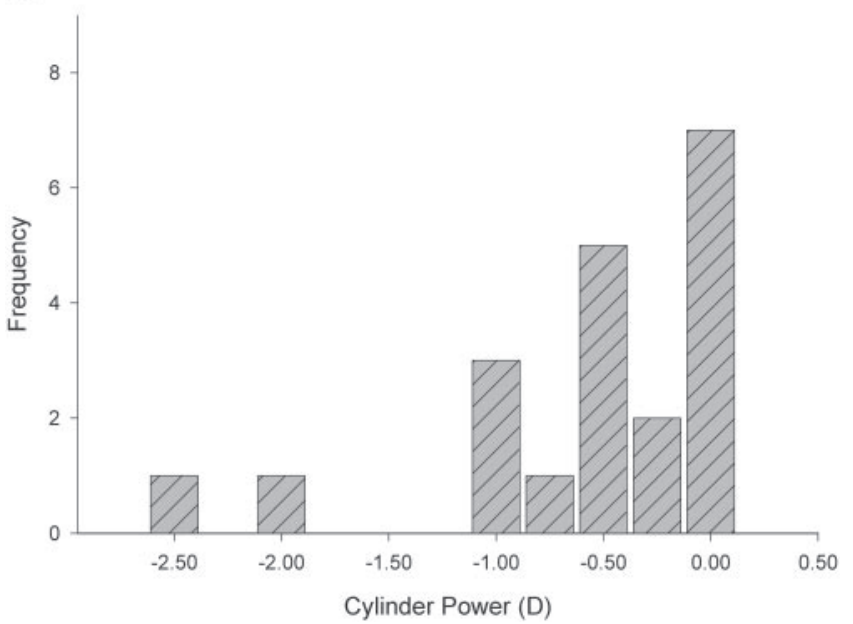

FiguRE 1. (A) Frequency of residual spherical and mean spherical refractive error and (B) percentage cylindrical error after IOL implantation surgery. Data are from the 4- to 6-month follow-up. $n=20$ eyes.

tance acuity was $0.007 \pm 0.16 \log$ MAR for high-contrast and $0.13 \pm 0.22 \log$ MAR for low-contrast letters. The mean near acuity at $40 \mathrm{~cm}$ was $0.60 \pm 0.09 \log$ MAR and was correlated with pupil size $(r=0.68, P<0.01)$.

The subjective amplitude of accommodation measured using the RAF rule averaged $2.24 \pm 0.42 \mathrm{D}$ (range, $1.5-2.5 \mathrm{D}$ ). Pupil size was correlated with the subjective amplitude of accommodation $(r=0.66)$. The three eyes with a pupil size of $>6 \mathrm{~mm}$ had an amplitude of $1.5 \mathrm{D}$, whereas all other eyes had an amplitude of accommodation between 2.0 and 3.0 D. The larger pupil size occurred in younger subjects, and measures were taken in the dark with the wavefront sensor (Zywave; Bausch \& Lomb) using infrared light.

The static objective amplitude of accommodation calculated from stimulus response curves measured with the PowerRefractor averaged $0.32 \pm 0.23 \mathrm{D}$ (range, $0.10-0.75$; Fig. 2). When measured by the SRW-5000, the static objective amplitude of accommodation averaged $0.72 \pm 0.38 \mathrm{D}$ (range, 0.17 1.16; Fig. 2). Quadratic curve fitting over the 0.17- to 4.00-D stimulus range showed a stronger agreement with the SRW$5000\left(r^{2}=0.97\right)$ than with the PowerRefractor $\left(r^{2}=0.84\right)$. Linear fitting of the portion of the stimulus response curve, normally considered to be linear $(1.0-4.0 \mathrm{D})$, also showed a stronger agreement with the SRW-5000 (slope, $0.18 ; r^{2}=0.95$ )

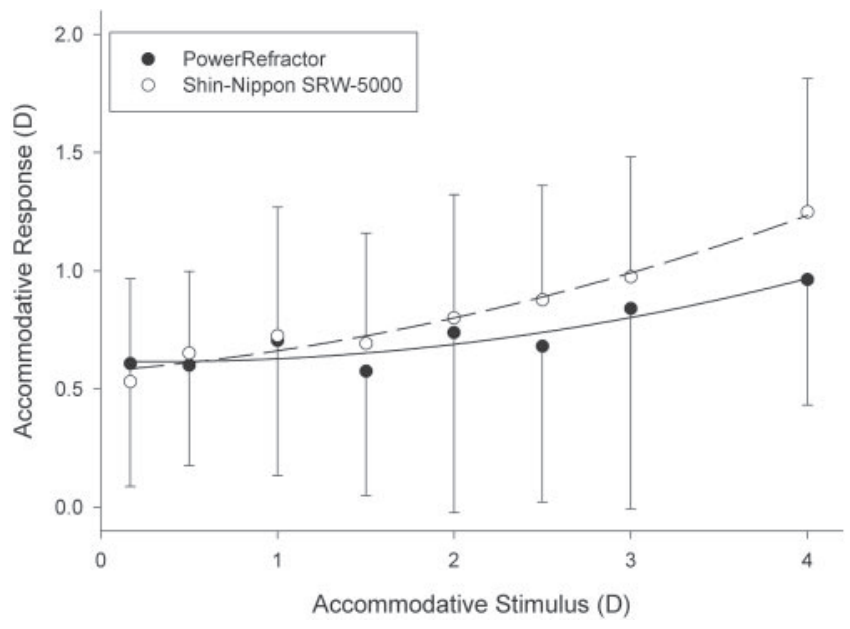

FIGURE 2. Accommodative stimulus response curve as measured with the PowerRefractor and the SRW-5000. Data are from the 4- to 6-month follow-up. $n=20$ eyes. Error bars, $\pm 1 \mathrm{SD}$.

than with the PowerRefractor (slope, $0.11 ; r^{2}=0.77$ ). Examining individual stimulus response curves shows that there are several different profiles to the graphs. There was a linear increase in accommodative response with increasing stimulus in four eyes, an increase followed by a decrease in four eyes, an increase only at higher levels of stimulus demand in three eyes, and no apparent increase in accommodative response in seven eyes. The two eyes of those subjects with bilateral implants usually showed a similar pattern.

The average stimulus response vergence slope measured with the PowerRefractor in those subjects with binocular implants was $0.74\left(r^{2}=0.93\right.$; Fig. 3). The individual stimulus response vergence slopes averaged $1.33 \pm 0.95\left(r^{2}=0.84 \pm\right.$ $0.16)$. The pupil size decreased with increasing accommodative stimulus demand (decreasing stimulus distance) by $0.10 \pm$ $0.10 \mathrm{~mm} / \mathrm{D}$ of accommodative stimulus $\left(r^{2}=0.84\right.$; Fig. 4).

The average dynamic amplitude of accommodation measured by the SRW-5000 was $0.71 \pm 0.47 \mathrm{D}$ (range, 0.31-1.56 D) with a lag time behind the target of $0.50 \pm 0.48$ seconds (Fig. 5). There was no significant difference between an individual's static and dynamic amplitude of accommodation (Fig. 6). There was no significant correlation between the static

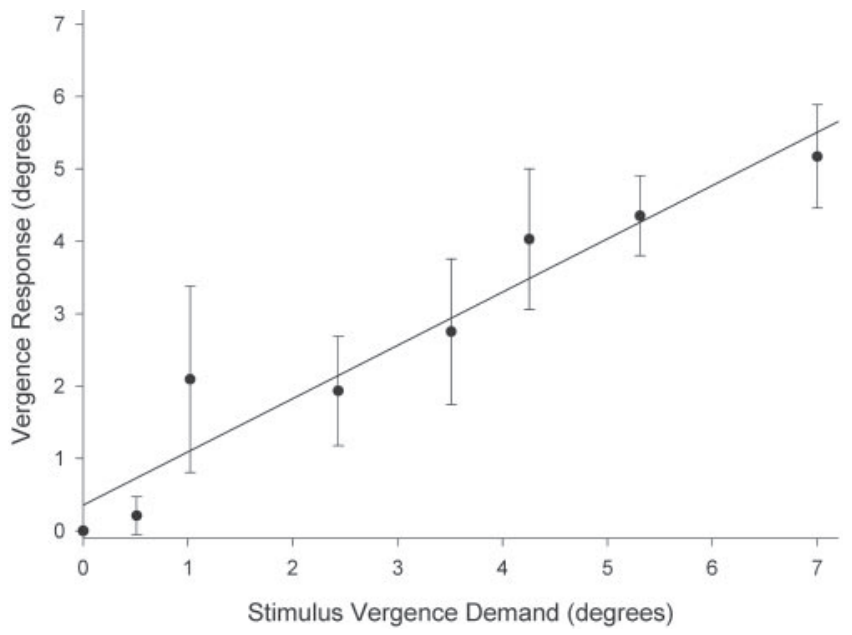

Figure 3. Vergence stimulus response measured with the PowerRefractor. Data are from the 4- to 6-month follow-up. $n=8$ subjects with $1 \mathrm{CU}$ IOLs in both eyes. Error bars, $\pm 1 \mathrm{SD}$. 


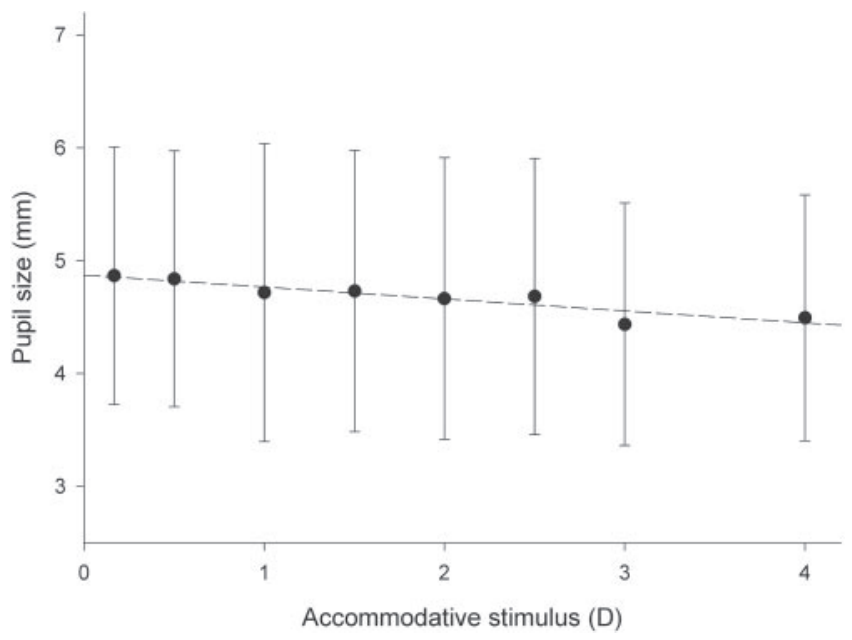

FIGURE 4. Pupil size compared with accommodative demand. Data are from the 4 - to 6-month follow-up. $n=20$ eyes. Error bars, \pm 1 SD

amplitude of accommodation and demographic characteristics, such as age $(r=0.32 ; P=0.21)$, time after surgery $(r=0.03$; $P=0.91)$, MSE $(r=0.36 ; P=0.16)$, corrected distance visual acuity $(r=0.22 ; P=0.40)$, corrected near acuity $(r=0.08$; $P=0.77)$, pupil size $(\mathrm{r}=-0.07 ; P=0.80)$, or time lag $(r=$ $0.08 ; P=0.77$ ).

Aberrometry showed a mean decrease in power (PPR) of the lens-eye combination from the center of the pupil to the periphery in all subjects of $-0.38 \pm 0.28 \mathrm{D} / \mathrm{mm}$ (Fig. 7).

There was no correlation between the power (13.0-25.0 D) of the implanted 1CU IOL and the objective static $\left(r^{2}=0.004\right.$, $P=0.79)$ and dynamic $\left(r^{2}=0.002, P=0.85\right)$ amplitude of accommodation, but there was a significant correlation $\left(r^{2}=\right.$ $0.42, P<0.01$ ) with the subjective amplitude of accommodation.

Two years after surgery subjects' refraction had become more myopic by $-0.26 \pm 0.59 \mathrm{D}(P<0.05)$. Best corrected distance visual acuity remained relatively unchanged (change, $0.01 \pm 0.22 \log$ MAR, $P=0.80$ ) over the first 2 years after lens implantation, but near visual acuity deteriorated (by $0.12 \pm$ $0.12 \log$ MAR, $P<0.01)$. In terms of focusing performance, the objective accommodative stimulus response curve had decreased (by $-0.19 \pm 0.44 \mathrm{D}, P=0.13$ ) as had the subjective

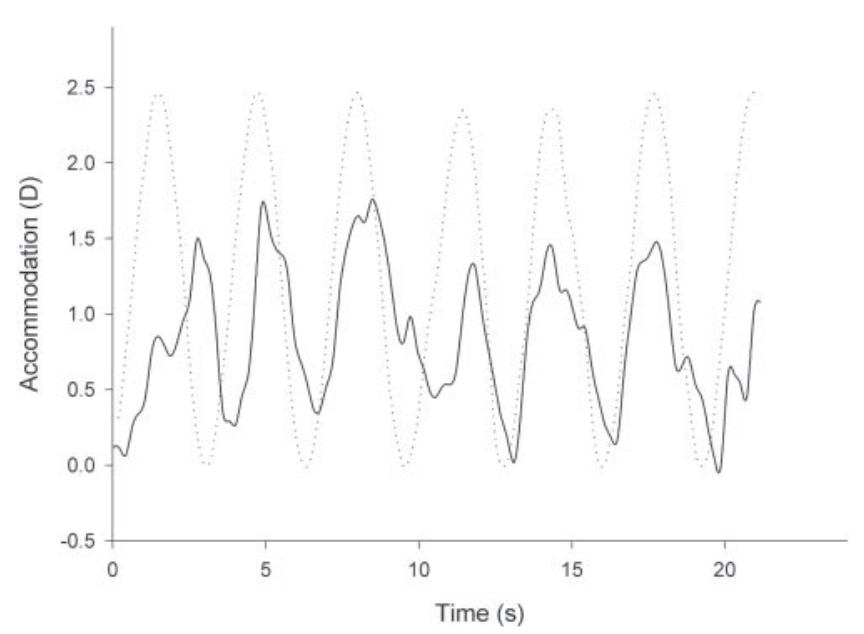

Figure 5. An example of the dynamic trace (solid trace) compared with the target demand (dashed trace) of one subject who showed a relatively high dynamic amplitude of accommodation (1.10 $\pm 0.16 \mathrm{D})$.

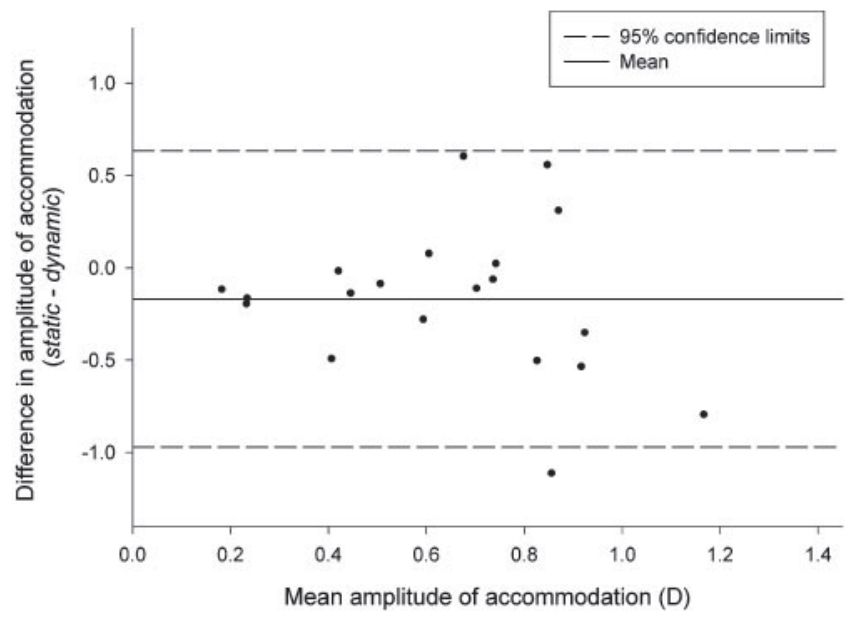

FIGURE 6. The difference between the static and dynamic objective amplitude of accommodation measured with the SRW-5000 versus the mean accommodative amplitude. ${ }^{44}$ Data are from the 4 - to 6-month follow-up. $n=20$ eyes.

amplitude of accommodation (by $-0.25 \pm 0.59 \mathrm{D}, P=0.12$ ), but not significantly. Posterior subcapsular thickening was mild to marked in 16 eyes, with 10 eyes having had YAG laser capsulotomy performed. No other complications were noted.

\section{Discussion}

The proposed mechanism of an anterior shift of an IOL from contractions of the ciliary body with accommodative effort is the closest mimic of the natural accommodative response presently available. ${ }^{17-19}$ The subjective amplitude of accommodation reported by several studies, and found in the present study, suggest a mean near point of between 42 and $75 \mathrm{~cm}$, which should be enough to allow a comfortable posture while reading. ${ }^{20-25}$ However, the anterior shift in IOL is one of several factors contributing to the subjective amplitude of accommodation. The near point of accommodation is also benefited by leaving the patient slightly myopic in correction, as was the case in the population examined.

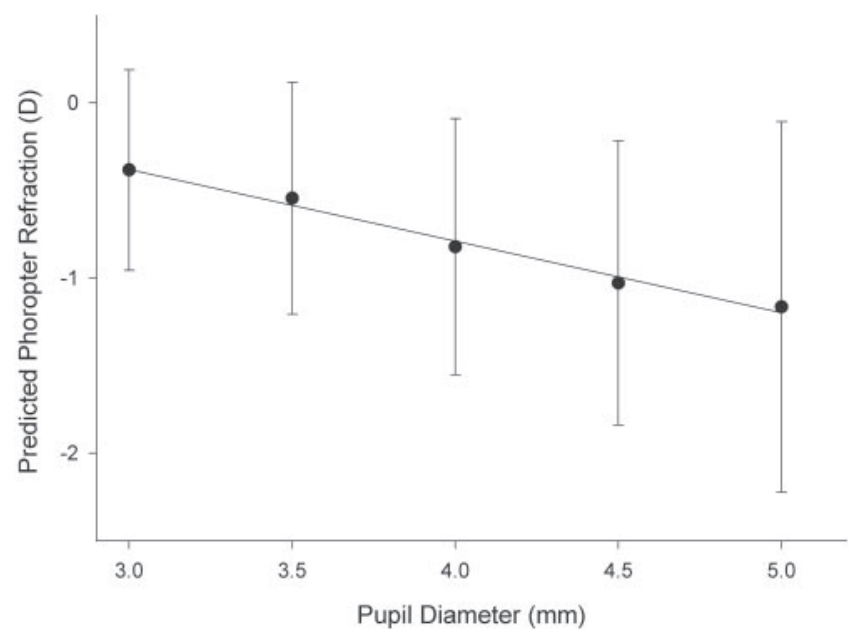

FIGURE 7. Change in aberrometer-predicted phoroptor-determined refraction from the pupil center. Data are from the 4- to 6-month follow-up. $n=20$ eyes, although readings at $5 \mathrm{~mm}$ were obtained in only 13 . Error bars, \pm 1 SD. 
Quantification of IOL movement has been performed before and after ciliary muscle contraction induced by pharmacological agents, rather than accommodation to a target of known demand, and hence the modeled accommodative results are difficult to compare with subjective findings. ${ }^{22,24,25,27-30}$ Attempts to quantify the range of accommodation objectively, such as streak retinoscopy and photoretinoscopy, have only examined the difference between two distances $(5.00$ and $0.35 \mathrm{~m})$, and they presume that these relate to the extremes of the accommodative range. ${ }^{22,24,25}$ Also streak retinoscopy relies on the subjective interpretation of the movement of the light reflex across the pupil, and photorefraction accuracy has been questioned. ${ }^{33,41}$ The objective amplitude of accommodation as measured by photorefraction was significantly lower in this study than by the well-validated SRW-5000. ${ }^{34}$ Unlike the SRW-5000, photorefraction examines the light reflex across the whole pupil and therefore is influenced by lens aberrations and pupil size changes.

Although the average stimulus response curve was linear over the 1.0- to 4.0-D range, individual curves showed considerable variability. Therefore determining the difference between the objective accommodative response at just two accommodative demands is unlikely to reflect the true accommodative range of an individual. The results also indicate the value of future studies that examine the ability of an individual to maintain accommodation at a set accommodative demand, rather than just measuring a static response. Unlike the accommodative response, the vergence response of individuals with binocular 1CU IOL implants was linear, although of reduced amplitude compared with that expected over a 6.0to $0.25-\mathrm{m}$ range (a slope of 0.74 compared with 1.00 predicted). The ability to track a dynamic target was similar to that recorded previously in prepresbyopes, ${ }^{38}$ although the amplitude was restricted to that noted by static measurement.

Best corrected distance acuity was excellent in all cases, with an ability to resolve low-contrast letters as well as do young healthy individuals, ${ }^{42}$ unlike that previously found with multifocal IOLs. ${ }^{11,12}$ The purpose of the surgeons was to leave the eyes very slightly myopic when choosing the IOL power from the biometry results. The near acuity at $40 \mathrm{~cm}$ was sufficient to read book or newspaper print with relative ease (approximately $\mathrm{N} 5$ point or $0.6 \mathrm{M}$ units). The subjective average amplitude of accommodation (2.24 D) could be accounted for by the dynamic objective accommodative range $(0.72 \mathrm{D})$, the subjective amplitude of accommodation found with a single-piece IOL $(0.42-1.08 \mathrm{D}),{ }^{22,25}$ and the aspheric nature of the lens $(-1.75 \mathrm{D}$ from the aberrometry result with a $4.6 \mathrm{~mm}$ average pupil size). The combination of these factors accounts for more than the subjective accommodative range, suggesting that they may interact rather than be additive. The increased depth of focus of the human eye resulting from the change in pupil size (of on average $0.43 \mathrm{~mm}$ ) is predicted to be minimal $(<0.05 \mathrm{D}){ }^{43}$

The refraction and distance visual acuity appeared to be relatively stable over a 2 -year period after implantation of the $1 \mathrm{CU}$ lens, in support of previous findings over 1 year. ${ }^{31} \mathrm{How}-$ ever, near visual acuity was reduced, accompanied by a decrease in the subjective and objective amplitude of accommodation.

In conclusion, the objective accommodating effects of the $1 \mathrm{CU}$ lens appear to be limited, although patients are able to track a moving target and achieve adequate acuity and contrast sensitivity for most visual tasks at distance and near. The average dynamic objective accommodative response to a moving stimulus was similar in amplitude to the objective static accommodative response, although the variability suggests both measures to be important. The pseudophakic accommodative response was similar in dynamics to that of prepresby- opic accommodation. Subjective and objective accommodation, however, had declined at the 2-year follow-up. The greater subjective, than objective, amplitude of accommodation most likely results from the interaction between the depth of focus of the eye and the aspheric nature of the 1CU IOL.

\section{References}

1. Gilmartin B. The etiology of presbyopia: a summary of the role of lenticular and extralenticular structures. Opbthalmic Pbysiol Opt. 1995; 15:431-437.

2. Charman WN. Restoring accommodation to the presbyopic eyehow do we measure success? J Cataract Refract Surg. 2003;29: 2251-2254.

3. Swegmark G. Studies with impedance cyclography on human accommodation at different ages. Acta Opbthalmol. 1969;47: 1186-1206.

4. Bacskulin A, Gast R, Bergmann U, Guthoff R. Ultrasound biomicroscopy imaging of accommodative configuration changes in the presbyopic ciliary body. Ophthalmologe. 1996;93:199-203.

5. Strenk SA, Semmlow JL, Strenk LM, Munoz P, Gronlund-Jacob J, DeMarco JK. Age-related changes in human ciliary muscle and lens: a magnetic resonance imaging study. Invest Ophthalmol Vis Sci. 1999; 40:1162-1169.

6. Glasser A, Campbell MCW. Biometric, optical and physical changes in the isolated human crystalline lens with age in relation to presbyopia. Vis Res. 1999;39:1991-2015.

7. Schachar RA. The correction of presbyopia. Int Opbthalmol Clin. 2001;41:51-70.

8. Gray PJ, Lyall MG. Diffractive multifocal intraocular lens implants for unilateral cataracts in prepresbyopic patients. $\mathrm{Br} \mathrm{J}$ Ophthalmol. 1992;76:336-337.

9. Javitt JC, Steinert RF. Cataract extraction with multifocal intraocular lens implantation: a multinational clinical trial evaluating clinical, functional, and quality-of-life outcomes. Ophthalmology. 2000;107:2040-2048.

10. Kamlesh MS, Dadeya S, Kaushik S. Contrast sensitivity and depth of focus with aspheric multifocal versus conventional monofocal intraocular lens. Can J Opbthalmol. 2001;36:197-201.

11. Montés-Micó R, Alió JL. Distance and near contrast sensitivity function after multifocal intraocular lens implantation. J Cataract Refract Surg. 2003;29:703-711.

12. Slagsvold JE. $3 \mathrm{M}$ diffractive multifocal intraocular lens: eight year follow-up. J Cataract Refract Surg. 2000;26:402-407.

13. Schmitz S, Dick HB, Krummenauer F, Schwenn O, Krist R. Contrast sensitivity and glare disability by halogen light after monofocal and multifocal lens implantation. Br J Opbthalmol. 2000;84: 1109-1112.

14. Haefliger E, Parel JM, Fantes F, et al. Accommodation of an endocapsular silicone lens (phaco-ersatz) in the nonhuman primate. opbthalmology. 1987;94:471-477.

15. Nishi O, Nakai Y, Yamada Y, Mizumoto Y. Amplitudes of accommodation of primate lenses refilled with two types of inflatable endocapsular balloons. Arch Ophthalmol. 1993;111:1677-1684.

16. Young E. Gel puts springiness back into old lenses. New Scientist. 2003;179:19.

17. Hara T, Hara T, Yasuda A, Yamada Y. Accommodative intraocular lens with spring action: Part 1. Design and placement in an excised animal eye. Ophthalmic Surg. 1990;21:128-133.

18. Legeais JM, Werner L, Werner L, Abenhaim A, Renard G. Pseudoaccommodation: BioComFold versus a foldable silicone intraocular lens. J Cataract Refract Surg. 1999;25:262-267.

19. Cumming JS, Slade SG, Chayet A. Clinical evaluation of the model AT-45 silicone accommodating intraocular lens: results of feasibility and the initial phase of a Food and Drug Administration clinical trial. The AT-45 Study Group. Ophthalmology. 2001;108:20052009.

20. Nakazawa M, Ohtsuki K. Apparent accommodation in pseudophakic eyes after implantation of posterior chamber intraocular lenses. Am J Opbthalmol. 1983;96:435-438.

21. Nakazawa M, Ohtsuki K. Apparent accommodation in pseudophakic eyes after implantation of posterior chamber intraocular lenses: optical analysis. Invest Ophthalmol Vis Sci. 1984;25:1458-1460. 
22. Kuchle M, Nguyen NX, Langenbucher A, Gusek-Schneider GC, Seitz B, Hanna KD. Implantation of a new accommodative posterior chamber intraocular lens. J Refract Surg. 2002;18:208-216.

23. Mastropasqua L, Toto L, Nubile M, Falconio G, Ballone E. Clinical study of the 1CU accommodating intraocular lens. J Cataract Refract Surg. 2003;29:1307-1312.

24. Langenbucher A, Huber S, Nguyen NX, Seitz B, Kuchle M. Cardinal points and image-object magnification with an accommodative lens implant (1 CU). Ophthalmic Physiol Opt. 2003;23:61-70.

25. Langenbucher A, Huber S, Nguyen NX, Seitz B, Ggusek-Scheider GC, Kuchle M. Measurement of accommodation after implantation of an accommodating posterior chamber intraocular lens. J Cataract Refract Surg. 2003;29:677-685.

26. Dick HB, Kaiser S. Dynamic aberrometry during accommodation of phakic eyes and eyes with potentially accommodative intraocular lenses. Ophthalmologe. 2002;99:825-834.

27. Lea SJH, Rubenstein PM, Snead MP, Haworth SM. Pseudophakic accommodation? - a study of the stability of the capsular bag supported, one piece rigid tripod or soft flexible implants. $\mathrm{Br} J$ Ophthalmol. 1990;74:22-25.

28. Ravalico G, Baccara F. Apparent accommodation in pseudophakic eyes. Acta Ophthalmol. 1990;68:604-606.

29. Auffarth GU, Schmidbauer J, Becker KA, Rabsilber TM, Apple DJ. Miyake-Apple video analysis of movement patterns of an accommodative intraocular lens implant. Ophthalmologe. 2002;99:811814 .

30. Findl $\mathrm{O}$, Kiss $\mathrm{B}$, Petternel $\mathrm{V}$, et al. Intraocular lens movement caused by ciliary muscle contraction. J Cataract Refract Surg. 2003;29:669-670.

31. Kuchle M, Seitz B, Langenbucher A, Martus P, Nguyen NX, Erlangen Accommodative Intraocular Lens Study Group. Stability of refraction, accommodation, and lens position after implantation of the 1CU accommodating posterior chamber intraocular lens $J$ Cataract Refract Surg. 2003;29:2324-2329.

32. Bailey IL, Lovie JE. New design principles for visual acuity letter charts. Am J Optom Physiol Opt. 1976;53:740-745.
33. Hunt OA, Wolffsohn JS, Gilmartin B. Evaluation of the measurement of refractive error by the PowerRefractor: a remote, continuous and binocular measurement system of oculomotor function. Br J Ophthalmol. 2003;87:1504-1508.

34. Mallen EAH, Wolffsohn JS, Gilmartin B, Tsujimura S. Clinical evaluation of the Shin-Nippon SRW-5000 autorefractor in adults. Ophthalmic Physiol Opt. 2001;21:101-107.

35. Stark LR, Atchison DA. Subject instructions and methods of target presentation in accommodation research. Invest Ophthalmol Vis Sci. 1994;35:528-537.

36. Wolffsohn JS, Hunt OA, Gilmartin B. Continuous measurement of accommodation in human factor applications. Ophthalmic Physiol Opt. 2002;22:380-384.

37. Johnson CA. Effect of luminance and stimulus distance on accommodation and visual resolution. J Opt Soc Am. 1976;66:138-142.

38. Wolffsohn JS, Gilmartin B, Mallen EAH, Tsujimura S. Continuous recording of accommodation and pupil size using the Shin-Nippon SRW-5000 autorefractor. Ophthalmic Physiol Opt. 2001;21:108113.

39. Wolffsohn JS, Gilmartin B, Li RW-H, et al. Accommodative hysteresis in preadolescent Hong Kong Chinese. Invest Ophthalmol Vis Sci. 2003;44:2284-2289.

40. Walsh G, Charman WN. Measurement of the axial wavefront aberration of the human eye. Ophthalmic Physiol Opt. 1985;5:2331.

41. Seidemann A, Schaeffel F. An evaluation of the lag of accommodation using photorefraction. Vision Res. 2003;43:419-430.

42. Reeves BC, Wood JM, Hill AR. Reliability of high-contrast and low-contrast letter charts. Ophthalmic Physiol Opt. 1993;13:1726.

43. Atchison DA, Charman WN, Woods RL. Subjective depth-of-focus of the eye. Optom Vis Sci. 1997;74:511-520.

44. Bland JM, Altman DG. Statistical methods for assessing agreement between two methods of clinical measurement. Lancet. 1986;1: 307-310. 